\title{
Reminder Cards and Immunization Rates Among Latinos and the Rural Poor in Northeast Colorado
}

\author{
Paul Hicks, MD, Gillian A. M. Tarr, MPH, and Ximena Prieto Hicks, MD
}

Objective: Immunization rates are static in the United States. Risk factors for not being up to date (UTD) include ethnicity and lower socioeconomic status. Reminder cards increase immunization rates in urban settings. Their effect in poor, Latino, and rural children is unknown.

Background: Language-appropriate reminder cards were sent to active patients not UTD listing the vaccines missing; the card served as the physician order for the vaccine. Missed opportunities were addressed through discussion with staff and posters in patient care rooms. UTD rates before and after intervention were measured.

Results: Dual-purpose reminder/order cards increased the rate of UTD from $61.3 \%$ to $73.4 \%$; children living near the clinic, patients who speak only Spanish, and Latinos overall showed preferential effectiveness. Children eligible to participate in the Vaccines for Children program had similar increases in UTD rates but had lower baseline and final UTD rates than did children not eligible for the Vaccines for Children program. The rate of missed opportunities did not change. The number of children to whom reminder cards needed to be sent for them to become fully immunized is 8 (number needed to treat).

Conclusions: In poor, rural, and Latino populations, language-appropriate reminder/order cards increase immunization rates. (J Am Board Fam Med 2007;20:581-586.)

Immunization rates in the United States have reached a plateau in the last several years; several states, including Colorado, show rates far below national averages. ${ }^{1,2}$ After steadily rising through the 1980s, minimal improvement was seen in the 1990s. There are many theories as to why this glass ceiling exists. Among them are parental concerns about vaccine side effects and safety, the increasing complexity of the recommended immunization schedule, and competing demands in a busy office setting. Missed opportunities represent a special concern because they occur with high frequency and account for much of the immunization delay seen in practice, specifically for at-risk children. ${ }^{3,4}$

It is clear, however, that for some populations, the ceiling is lower than for others. Minorities and the poor have higher rates of not being up to date

This article was externally peer reviewed.

Submitted 5 May 2006; revised 30 January 2007; accepted 5 February 2007.

From the Salud Family Health Center, Fort Lupton, CO (PH, XPH); and Department of Epidemiology, Johns Hopkins Bloomberg School of Public Health, Baltimore, MD (GM).

Funding: none.

Conflict of interest: none declared.

Corresponding author: Paul Hicks, MD, Salud Family Health Center, 1115 Second St, Fort Lupton, CO 80621 (E-mail: phicks@saludclinic.org). than do wealthier or white children. ${ }^{5-11}$ The consequence of incomplete immunization is the persistent occurrence of vaccine-preventable diseases.

Many strategies have been recommended to improve immunization rates. ${ }^{12-19}$ The Vaccine for Children (VFC) program was developed to help ameliorate the inequities in vaccinations inherent in people living in poverty and to increase minorities' access to free vaccines. $^{20,21}$ The use of computer-based vaccine registries is increasing in the United States, with over half of all children younger than 6 years of age enrolled in 2005. ${ }^{22}$ These registries provide the benefits of accessibility in many patient care settings, thereby decreasing chances that one site will inappropriately vaccinate a child. These and other arguments in their favor have been extensively published. ${ }^{12,23-26}$ Arguments against these registries include the large labor costs of data entry and inconsistent or incomplete data entry leading to the assessment of lower UTD rates using the registries compared with chart reviews. ${ }^{27-30}$

Recall and reminder cards seem to have an overall positive effect on immunization rates in both children and adults. ${ }^{31-33}$ The effect is less in lowerincome populations. Previous work in our institution revealed that reminder cards were ineffective 
in increasing the frequency of getting laboratory tests performed among adult patients with diabetes (unpublished data, Hicks, 2001). However, the effectiveness of recall and reminder cards in the immunization rates of healthy children was not evaluated in that study. Our intention with the current study was to determine whether the use of patient reminder cards and a simple office-based intervention to decrease missed opportunities would improve the number of children UTD with recommended immunizations in a low-income, rural, and Latino population.

\section{Methods}

Salud Family Health Center (Salud) is a nonprofit community health center serving Latinos and the poor in rural Northeastern Colorado. The center in Fort Morgan serves a population of which $75 \%$ are Latino and $75 \%$ of these are monolingual Spanish speakers. Thirty-five percent of patients seen in the clinic are at or below federal limits for poverty and $90 \%$ are living below $200 \%$ of the poverty level. The Continuous Quality Improvement Committee at Salud commissioned and monitored this project.

The intervention took place from February to November 2002 and had 2 arms: (1) the use of reminder/order cards sent in the primary language of the patient, and (2) placement of posters in the examination rooms reminding patients and physicians to vaccinate the children while they were in the clinic for unrelated reasons. The aims of these were to address UTD rates by increasing the accessing of vaccine services as well as decreasing missed opportunities.

Up to 3 reminder cards were sent by first-class mail in Spanish or English (depending on the primary language listed in the chart of the patient) to all children not UTD. They were sent to the address the patient's family had supplied at the most recent visit to the clinic. These cards included an introduction from the clinic and specified the type and number of vaccines that the child did not appear to have had. It invited the family to bring the child and present the card to the staff, which would serve as a physician order for the nursing staff to give the vaccine. Staff was instructed that patients presenting with cards would receive the immunizations without a physician visit. Missed opportunities were addressed by a presentation given to clinic staff and placing bilingual posters in patient rooms to remind parents, nurses, and physicians to immunize the children during that same visit.

One of the authors (GM) performed chart reviews on all children 35 months of age or younger who had been seen at the clinic. Demographic information collected included age, payer status, primary language, place of birth, and distance of the patient's home from the clinic (3 cutoff values were used for this: within the same rural town, from a nearby town 9 miles away, or from a further distance). Quality and consistency of the review was confirmed with regular follow up with another author $(\mathrm{PH})$. Uncertain or unclear issues were resolved by consensus of all 3 of the authors. Reasons for exclusion included patients who had moved and had not left a forwarding address, patients who had transferred to other care providers outside of the Salud system, patients who had received 3 reminder cards but had not responded, and patients considered inactive (defined as no visit in more than 1 year). In addition, the charts of 3 patients had been lost or had expired. For the historical controls to be comparable by age to the postintervention group, only children aged 13 to 35 months at either the beginning or end of the intervention were analyzed. This yielded 240 patients at baseline and 263 patients after intervention.

Children were considered UTD if they had completed the series according to adjusted $\mathrm{Na}$ tional Immunization Program standards. During the time of the study, significant shortages existed for the diphtheria/tetanus/acellular pertussis vaccine (DTaP) and national recommendations were that children receive only 3 doses of DTaP. As such, the standard of $4 \mathrm{DTaP}, 3$ polio vaccines, 3 Haemophilus influenzae type $\mathrm{B}$ vaccines, 3 hepatitis $B$ vaccines, 1 measles/mumps/rubella vaccine, and 1 varicella vaccine by 19 months of age was modified to include only 3 DTaP doses. The goal for 13to 18 -month-olds of $3 \mathrm{DTaP}, 2$ polio vaccines, 2 hepatitis $\mathrm{B}$ vaccines, and $2 H$. influenzae type $\mathrm{B}$ vaccines was unaffected by the DTaP shortage.

Children were considered to have a missed opportunity if the child visited the clinic during or after the recommended age range for a vaccine, did not have a fever of $102^{\circ} \mathrm{F}$ or greater, and did not receive the vaccine in that visit or during the recommended time interval of the Recommended Childhood Immunization Schedule from the Cen- 
Table 1. Number of Children Up to Date

\begin{tabular}{lcc}
\hline Shot Type & $\begin{array}{c}\text { Number at } \\
\text { Baseline } \\
{[\mathrm{n}(\%)]}\end{array}$ & $\begin{array}{c}\text { Number After } \\
\text { Intervention } \\
{[\mathrm{n}(\%)]}\end{array}$ \\
\hline $\begin{array}{l}\text { Completely Immunized } \\
\text { Per Antigen }\end{array}$ & $147(61.3)$ & $193(73.4)^{*}$ \\
DTaP & $211(87.9)$ & $239(91.2)$ \\
IPV & $211(87.9)$ & $239(91.2)$ \\
Hib & $169(70.4)$ & $205(79.5)^{*}$ \\
HepB & $195(81.3)$ & $223(86.4)$ \\
MMR & $149(86.6)$ & $163(85.3)$ \\
Varicella & $138(80.2)$ & $157(82.2)$ \\
\hline
\end{tabular}

*Postintervention rate is significantly different from baseline, $P<.05$.

$\mathrm{DTaP}$, diphtheria/tetanus/acellular pertussis vaccine; IPV, polio vaccine; Hib, Haemophilus influenzae type B vaccine; HepB, hepatitis $B$ vaccine; MMR, measles, mumps, and rubella vaccine.

ters for Disease Control, which was updated in 2002.

A Fisher exact test was used to determine whether the recall card intervention affected overall and individual UTD rates. This test was also used to examine the comparability of the pre- and postintervention groups and to stratify the change in UTD rates by potential confounders. Potential confounders were obtained during the chart review and included age, primary language, race and ethnicity, socioeconomic status (for which the type of health insurance was used as a surrogate), the distance from the family's home to the clinic, and place of birth. The second arm of the project was evaluated by comparing missed opportunities per child-month before and after intervention. Intercooled Stata 8.2 (StataCorp, LP, College Station, $\mathrm{TX})$ was used for all statistical analyses.

\section{Results}

Reminder cards successfully increased immunization rates from $61.3 \%$ UTD on all 6 vaccines at the start of intervention to $73.4 \%$ UTD at termination $(P=.004$; Table 1). This is an absolute increase of $12.1 \%$ and a relative increase of $19.7 \%$. Increases were seen in almost all individual antigen types (Table 1), but the only statistically significant increase was in $H$. influenzae type $\mathrm{B}$ vaccination rates $(P=.023)$. Considering the number needed to treat, this increase translates into 8 children to whom recall cards would need to be sent for 1 to become fully immunized. The number of missed opportunities per child-month did not change $(z=0.073 ; P=.944)$.
Table 2. Number of Children Up to Date per National Institute of Standards

\begin{tabular}{lcc}
\hline Age & $\begin{array}{c}\text { Number at } \\
\text { Baseline } \\
{[\mathrm{n}(\%)]}\end{array}$ & $\begin{array}{c}\text { Number After } \\
\text { Intervention } \\
{[\mathrm{n}(\%)]}\end{array}$ \\
\hline 13 to 18 months & $38(55.9)$ & $55(77.5)^{*}$ \\
19 to 35 months & $109(63.4)$ & $138(71.9)$ \\
\hline
\end{tabular}

*Postintervention rate is significantly different from baseline, $P<.05$

The before intervention and after intervention groups did not differ in demographic characteristics, including age, distance of home from the clinic, primary language, ethnicity, insurance, and place of birth (data not shown). Stratifying UTD rates by each of these factors before and after intervention shows considerable differences in subgroups (Tables 2 and 3). An age of 13 to 18 months $(P=.011)$; living within 10 miles of the clinic $(P=$ $.021)$; speaking Spanish $(P=.013)$; being Hispanic

Table 3. Children Up to Date Based on Other Factors

\begin{tabular}{lrc}
\hline Factor & $\begin{array}{c}\text { Number at } \\
\text { Baseline } \\
{[\mathrm{n}(\%)]}\end{array}$ & $\begin{array}{c}\text { Number After } \\
\text { Intervention } \\
{[\mathrm{n}(\%)]}\end{array}$ \\
\hline Ethnicity & & \\
Hispanic & $119(60.1)$ & $157(73.4)^{*}$ \\
Non-Hispanic & $25(69.4)$ & $31(72.1)$ \\
Language preference & & \\
Spanish & $83(58.5)$ & $109(72.7)^{*}$ \\
English & $64(65.3)$ & $84(74.3)$ \\
Distance from clinic & & \\
Near to clinic (0-10 miles) & $131(59.5)$ & $174(72.8)^{*}$ \\
Far from clinic (>10 miles) & $16(84.2)$ & $16(80)$ \\
Place of birth & & \\
Morgan County & $110(63.2)$ & $152(75.6)^{*}$ \\
Other Colorado & $24(60.0)$ & $26(63.4)$ \\
Other United States & $8(47.1)$ & $12(75.0)$ \\
Foreign & $2(66.7)$ & $2(66.7)$ \\
Health insurance status & & \\
Uninsured & $20(69.0)$ & $27(71.1)$ \\
Medicaid/CHP + program & $72(55.0)$ & $104(68.9)^{*}$ \\
Private insurance & $55(68.8)$ & $62(83.8)^{*}$ \\
VFC program coverage & & \\
Covered by VFC & $131(60.4)$ & $172(71.4)^{*}$ \\
Not covered by VFC & $16(69.6)$ & $21(95.5)^{*}$ \\
\hline
\end{tabular}

*Postintervention rate is significantly different from baseline, $P<.05$.

$\mathrm{CHP}+$, Child Health Plan Plus (insurance plan for low income patients who do not qualify for Medicaid); VFC, Vaccine for Children. 
$(P=.005)$; having Medicaid or Child Health Plan

+ (another insurance plan for children of lower socioeconomic status) $(P=.042)$ or private $(P=$ $.047)$ insurance; and being born in Morgan County $(P=.010)$ were all associated with significant increases in UTD rates at the end of the intervention.

\section{Discussion}

The evaluation of our intervention shows that, in a primarily Latino population in a rural community health center setting, sending reminder cards, which also serve as a physician order and are written in the language of the patient, are an effective tool to increase immunization rates. It is reassuring that immunization rates for individual vaccines were high at baseline, with $70.4 \%$ to $87.9 \%$ of children UTD. Even with such comparatively high levels of immunization, though, recall cards still served to augment those rates.

Considering National Immunization Program recommendations, this evaluation serves to show the complexity of the interaction between being UTD for individual vaccines and being UTD for the full series of vaccines. UTD rates after intervention for the 19- to 35-month-old group were $71.9 \%$; rates were $77.5 \%$ for the 13 - to 18 -monthold group. However, as seen in Table 1, the UTD rates for the component vaccines were substantially higher. This suggests that the pool of children who are not UTD contains many children missing different vaccines instead of just a few children missing all them. If children are indeed missing only one or a few vaccines, the high number of missed opportunities could be responsible for the low overall UTD rates.

It was initially unclear why the intervention was not significant in the 19- to 35-month-old population. To help clarify, we stratified the UTD rates by age ranges and specific vaccines (data not shown). It was found that UTD rates for $H$. influenzae type $\mathrm{B}$ and hepatitis $\mathrm{B}$ vaccinations were significantly affected at lower age ranges but not at higher ones. At these higher ages, UTD rates for individual vaccines were approximately $90 \%$ for all but 1 vaccine (of 6 ). It is possible that the relative change in being UTD would not be so great in this group, given a higher baseline UTD rate.

It is interesting to note the increased effectiveness among Latinos and monolingual Spanish speakers more than in other populations. It may be that more recent immigrants are more likely to follow a physician's advice. Whether this is a function of ethnicity or other variables is unclear. It would be interesting to assess levels of acculturation and the degree of adherence to recommendations from health care providers in future studies. Lastly, the fact that the card itself served as a physician order authorizing the staff to provide the vaccine, thereby eliminating some wait time in the clinic, may have had some effect. It is theorized that Latinos in the community were more likely to be in potentially lower paying jobs, making time off to come to the doctor more of a hardship. Limiting the time off needed may have preferentially benefited this group.

This study also supports both the effectiveness and limitations of the VFC program. Designed to decrease barriers and increase immunization rates for the poor, children eligible for VFC vaccine had statistically significant increases in UTD rates. They did not, however, reach the same level of complete immunization as did the cohort that was not eligible for the VFC program, suggesting that factors other than free vaccinations contribute to children not being fully immunized. Similarly, when stratified by insurance coverage (a proxy for socioeconomic status), children who were privately insured or covered by Medicaid and the Child Health Plan + had significant increases in UTD rates, with the former showing higher rates of immunization both before and after the intervention.

Despite the significant increases in immunization rates seen in this study, there is still much work to be done. The overall UTD rates were similar to other places in Colorado, which, at the time of this study, ranked 50th in the nation for vaccination rates. A significant portion of this may be attributed to missed opportunities. Although an argument may be made that 9 to 10 months is insufficient to change the culture of a busy outpatient clinic, the lack of any downward trend in the rate of missed opportunities would argue against that theory. More work is needed to identify low-cost, effective strategies to eliminate missed opportunities that are easy to implement in a busy outpatient setting.

There are several limitations to the study above. One of these is the lack of a prospective, blinded design. This was considered before implementing the program. But given previous successes with the use of reminder cards in UTD rates ${ }^{31,32}$ and the expected similarity in the groups, a historical con- 
trol seemed sufficient. Further, the lack of blinding did not seem to play a significant role in immunization-related behavior because the rate of missed opportunities did not change appreciably. Further justification for the use of historical controls is the demographic stability of the target population, making the populations similar. Lastly, we wanted to have sufficient sample size in the groups to maintain statistical power, which we felt would have been threatened by the use of more traditional models.

Other limitations include the $10 \%$ of individuals excluded from consideration because they had moved and not left forwarding addresses. This is a common finding in reminder card studies ${ }^{24}$ and the rates found here are within the range of those seen in other studies. Also important is the exclusion of patients who had not been seen in the previous 12 months and those who had been seen in this time frame but who did not respond to the 3 mailings. This practice of excluding nonresponders after 3 mailings (listing them as "missing or going elsewhere") is standard for data entry in the prominent immunization programs in current use. Although it does not follow outcomes for the patients nor the principle of intention to treat, it is the standard for this body of work $\mathrm{w}^{23,27,34,35}$ and our compliance with this practice allows our data to be compared with other published works.

As successful as the intervention was in increasing UTD rates in children, the chart review and reminder cards had to be generated manually. This required a large commitment of time and resources, which are often scarce in rural and community health center settings. As many offices turn to electronic medical records, incomplete records will decrease in frequency. Considering the cost of electronic medical records, the Centers for Disease Control has created the Comprehensive Clinic Assessment Software Application immunization registry $^{36}$ to serve as an intermediate step, which also can generate reminder cards. This free immunization program, if maintained, will probably have the same effect as the above intervention.

\section{Conclusions}

Reminder cards have been previously shown to be effective at increasing immunization rates in urban settings with patients of various socioeconomic status. Such interventions had not been studied in rural populations or in people with limited proficiency in speaking English. This study confirms that in a community with the majority of people being poor and Latino, language-appropriate reminder cards that also serve as a physician order increased UTD rates.

\section{References}

1. Teitelbaum MA, Edmunds M. Immunization and vaccine-preventable illness, United States 1992 to 1997. Stat Bull Metrop Insur Co. 1999;80:13-20.

2. Luman ET, Barker LE, Simpson DM, Rosewald LE, Szilagyi PG, Zhao Z. National, state and urban-area vaccination-coverage levels among children aged 19-35 months, United States, 1999. Am J Prev Med 2001;20 Suppl 4:88-153.

3. Daley MF, Beaty BL, Barrow J, et al. Missed opportunities for influenza vaccination in children with chronic medical conditions. Arch Pediatr Adolesc Med 2005;159:986-91.

4. Minkovitz CS, Belote AD, Higman SM, Serwint JR, Weiner JP. Effectiveness of a practice-based intervention to increase vaccination rates and reduce missed opportunities. Arch Pediatr Adolesc Med 2001;155:382-6.

5. Slifkin RT, Clark SJ, Standhoy SE, Konrad TR. Public-sector immunization coverage in 11 states: the status of rural areas. J Rural Health 1997;13:33441.

6. Gore P, Madhavan S, Curry D, et al. Predictors of childhood immunization completion in a rural population. Soc Sci Med 1999;48:1011-27.

7. Lowery NE, Belansky ES, Siegel CD, Goodspeed JR, Harman CP, Steiner JF. Rural childhood immunization. Rates and demographic characteristics. J Fam Pract 1998;47:221-5.

8. Shefer AM, Luman ET, Lyons BH, et al. Vaccination status of children in the Women, Infants, and Children (WIC) program: are we doing enough to improve coverage? Am J Prev Med 2001;20 Suppl 4:47-54.

9. Brenner RA, Simons-Morton BG, Bhaskar B, Das A, Clemens JD, NIH-DC Initiative Immunization Working Group. Prevalence and predictors of immunization among inner-city infants: a birth cohort study. Pediatrics 2001;108:661-70.

10. Strine TW, Barker LE, Mokdad AH, Luman ET, Sutter RW, Chu SY. Vaccination coverage of foreignborn children 19-35 months of age: findings from the National Immunization Survey, 1999-2000. Pediatrics 2002;110(2 Pt 1):e15.

11. Wood D, Donald-Sherbourne C, Halfon N, et al. Factors related to immunization status among innercity Latino and African-American preschoolers. Pediatrics 1995;96(2 Pt 1):295-301.

12. Jenders RA, Dasgupta B, Mercedes D, Clayton PD. 
Design and implementation of a multi-institution immunization registry. Medinfo 1998;(9 Pt 1):45-9.

13. Bolton P, Holt E, Ross A, Hughart N, Guyer B. Estimating vaccination coverage using parental recall, vaccination cards, and medical records. Public Health Rep 1998;113:521-6.

14. Hellerstedt WL, Olson SM, Oswald JW, Pirie PL. Evaluation of a community-based program to improve infant immunization rates in rural Minnesota. Am J Prev Med 1999;16 Suppl 3:50-7.

15. Fairbrother G, Hanson KL, Friedman S, Butts GC. The impact of physician bonuses, enhanced fees, and feedback on childhood immunization coverage rates. Am J Public Health 1999;89:171-5.

16. Fairbrother G, Siegel MJ, Friedman S, Kory PD, Butts GC. Impact of financial incentives on documented immunization rates in the inner city: results of a randomized controlled trial. Ambul Pediatr 2001;1:206-12.

17. Sinn JS, Morrow AL, Finch AB. Improving immunization rates in private pediatric practices through physician leadership. Arch Pediatr Adolesc Med 1999; 153:597-603.

18. Szilagyi PG, Rodewald LE, Humiston SG, et al. Reducing missed opportunities for immunizations. Easier said than done. Arch Pediatr Adolesc Med 1996;150:1193-2000.

19. Hawe P, McKenzie N, Scurry R. Randomised controlled trial of the use of a modified postal reminder card on the uptake of measles vaccination. Arch Dis Child 1998;79:136-40.

20. Kauf TL. Are state immunization programs effective? Implications for the children's immunization initiative. Clin Ther 1998;20:806-19.

21. Fairbrother G, Friedman S, Hanson KL, Butts GC. Effect of the vaccines for children program on innercity neighborhood physicians. Arch Pediatr Adolesc Med 1997;151:1229-35.

22. Canavan BC, Kurilo M, Moss T, et al. Immunization information systems progress-United States, 2005. MMWR Morb Mortal Wkly Rep 2006;55:1327-9.

23. Kempe A, Steiner JF, Renfrew BL, Lowery E, Haas $\mathrm{K}$, Berman S. How much does a regional immunization registry increase documented immunization rates at primary care sites in rural Colorado? Ambul Pediatr 2001;1:213-6.

24. Stroud KM, Benjamin JT. Can accurate immuniza- tion rates be determined in a primary care clinic? J Med Assoc Ga 2002;91:27-30.

25. Renfrew BL, Kempe A, Lowery E, Chandramouli V, Steiner JF, Berman S. The impact of immunization aggregation on up-to-date rates- implication for immunization registries in rural areas. J Rural Health 2001;17:122-6.

26. Stille CJ, Christison-Lagay J. Determining immunization rates for inner-city infants: statewide registry data vs medical record review. Am J Public Health 2000;90:1613-5.

27. Smith RE, Eden AN. Assessing immunization rates in an ambulatory care setting. J Urban Health 2002; 79:219-24.

28. Kilasa MS, Chilkatowsky AP, Clarke KR, Lutz JP. How complete are immunization registries? The Philadelphia story. Ambul Pediatr 2006;6:21-4.

29. Kairys SW, Gubernick RS, Millican A, Adams WG. Using a registry to improve immunization delivery. Pediatr Ann 2006;35:500-6.

30. Khare M, Piccinino L, Barker LE, Linkins RW. Assessment of immunization registry databases as supplemental sources of data to improve ascertainment of vaccination coverage estimates in the national immunization survey. Arch Pediatr Adolesc Med 2006;160:838-42.

31. Szilagyi PG, Bordley C, Vann JC, et al. Effect of patient reminder/recall interventions on immunization rates. JAMA 2000;284:1820-7.

32. Kohrt AE, Korht LG. Improving immunization rates in pediatric practice. Pediatr Ann 2001;30:320-7.

33. Jacobson VJ, Szilagyi P. Patient reminder and patient recall systems to improve immunization rates. Cochrane Database Syst Rev 2005;3:CD003941.

34. Phibbs SL, Hambidge SJ, Steiner JF, Davidson AJ. The impact of inactive infants on clinic-based immunization rates. Ambul Pediatr 2006;6:173-7.

35. Renfew BL, Kempe A, Lowery E, Chandramouli V, Steiner JF, Berman S. The impact of immunization record aggregation on p-to-date rates- Implications for immunization registries in rural areas. J Rural Health 2001;17:122-6.

36. Centers for Disease Control and Prevention. User's Guide for the Windows Version of the Comprehensive Clinic Assessment Software Application. Atlanta (GA): Centers for Disease Control and Prevention [cited day month year]. Available at http//www. cdc.gov/vaccines/programs/cocasa/default.htm. Accessed 7 September 2007. 